\title{
SUBJETIVIDADE SUJEITADA E PRÁTICA PSICOLÓGICA: PERSPECTIVAS DO SUJEITO DA AÇÃO
}

\author{
Mériti de Souza* \\ Sidnei J. Munhoz**
}

\section{RESUMO}

O artigo problematiza leituras sobre o denominado sujeito da ação como associado à constituição grupal e as implicações dessas leituras na prática psicológica e na organização subjetiva. Para tanto, utiliza-se uma leitura interdisciplinar e aportes de disciplinas como a história e a psicanálise. A ênfase crítica recairá na lógica clássica, na identidade e na subjetividade sujeitada, que se apresentam como atemporais e universais na ação sobre a realidade. Problematizar a construção da subjetividade e as suas relaçôes com os modos de conhecer pode contribuir para o estabelecimento de referenciais teóricos e estratégias de intervenção críticos.

Palavras-chave: subjetividade; psicologia; psicanálise; identidade; ação.

\section{Abstract}

SUbJECTED SUBJECTIVITY AND PSYCHOLOGICAL PRACTICE: PERSPECTIVES IN AGENTS OF ACTION

Research problematizes readings on the so-called subject or agent of action as associated to group constitution and analyzes the implications of such interpretations in psychological practice

* Psicóloga (Universidade Estadual Paulista Júlio de Mesquita Filho - Unesp); Mestre em Educação (Universidade Estadual de Campinas - Unicamp); Doutora em Psicologia (Pontifícia Universidade Católica de São Paulo - PUC-SP) e Pós-Doutora (Centro de Estudos Sociais Universidade de Coimbra); Professora adjunta do Curso de Graduação e Programa de PósGraduação em Psicologia da Universidade Federal de Santa Catarina (UFSC).

** Graduação em História (Universidade Estadual Paulista Júlio de Mesquita Filho - Unesp); Mestrado em História (Universidade Estadual de Campinas - Unicamp); Doutorado em História Econômica (Universidade de São Paulo - USP) e Pós-Doutorado (Universidade Federal do Rio de Janeiro - UFRJ); Professor do Departamento de História da Universidade Estadual de Maringá (UEM) e da Pós-Graduação em História Comparada da Universidade Federal do Rio de Janeiro (UFRJ); Bolsista produtividade do CNPq. 
and in the constitution of subjectivity. The article is based on interdisciplinary readings and on different areas of knowledge so that identity references overlying the modern subject of action may be problematized. Critical emphasis is foregrounded on the classical logic, identity and subjected subjectivity as a-temporal and universal factors of action in the real world. The problematization of subjectivity's construction and its relationships with modes of knowledge will contribute towards the establishment of critical theoretic and strategic interventions.

Keywords: subjectivity; psychology; psychoanalysis; identity; action.

As profundas transformações políticas, econômicas e sociais ocorridas ao final do século XX colocaram grandes desafios para os estudos relacionados às ciências humanas. Como resultado desse complexo processo, assistiu-se a uma crise de paradigmas, uma vez que nenhum dos modelos explicativos então existentes dava conta da complexidade das relaçôes sociais então estabelecidas. Isso tudo engendrou problemas para os quais muito provavelmente não teremos respostas em termos de curto prazo. No entanto, se, de um lado, esse cenário apresenta dificuldades para as investigações no campo das humanidades, de outro, as dúvidas e as incertezas existentes estimulam novas indagaçõos em busca de alternativas para a compreensão das relações sociais contemporâneas e das constituiçōes subjetivas a elas agregadas. Em outras palavras, as experiências alicerçadas sob o impacto das novas configurações sociais, econômicas e históricas se articulam a modos de conhecer e de subjetivar, que demandam problematizar os referenciais teóricos e as estratégias de intervenção calcadas em leituras estabelecidas.

Neste artigo, delineamos algumas reflexôes voltadas à reconfiguração do debate sobre o sujeito da ação e o modo de subjetivar e de conhecer que o engendra e sustenta diferentes discursos e práticas contemporâneos. Pensamos que distintas áreas do conhecimento podem contribuir para problematizar o pressuposto que associa a ação sobre a realidade à figura do sujeito e da identidade coletiva. Problematizamos essa questão por entendermos que o sujeito é uma modalidade histórica de constituição subjetiva e a identidade coletiva uma modalidade de configuração grupal. Essas modalidades ganham hegemonia no cenário moderno em decorrência da sua associação a determinadas leituras sobre o conhecimento e sobre o subjetivo que instauram parâmetros que os definem como universais e verdadeiros. Nessa perspectiva, a ação fica adstrita às concepções epistêmicas e ontológicas calcadas na causalidade lógica formal e na metafísica da presença. Ato contínuo, esses modos de subjetivar e de conhecer ganham hegemonia e caucionam a relação causa e efeito; substantivam a subjetividade; dissociam o ativo do passivo; associam o grupal ao conjunto matemático da unidade e do idêntico; 
produzem a dicotomia sujeito e objeto. Desse modo, temos a produção da subjetividade sujeitada, ou seja, do sujeito constituído pela consciência reflexiva, conformada pelos atributos da razão e da ética, que lhe possibilita conhecer a si próprio e à realidade e, dessa forma, agir sobre ela.

A modalidade histórica de sujeito subsume a subjetividade à consciência; a redução do coletivo ao conjunto formado por unidades identitárias; a configuração da ciência restrita ao modelo cartesiano, kantiano e baconiano (Bachelard, 1996; Blanche, 1983; Canguilhem, 1977; Chauí, 1994, 1995; Morin, 2005a, 2005b; Prigogine, 1996; Santos, 1988, 2004). A partir desse cenário e das suas implicações na produção do conhecimento e nas práticas profissionais direcionadas ao trabalho crítico, consideramos pertinente problematizar a relação estabelecida entre a ação, o sujeito e a identidade coletiva, nas suas injunções com a rede societária contemporânea.

Conhecemos a necessidade de produção de novas formas de saber e fazer no campo da psicologia que correspondam às demandas de práticas que se pretendem para além dos pressupostos e modelos tradicionais que adotam concepções de sujeito e estratégias de intervenção calcadas no universal e em modelos definidos a priori.

Nesse contexto, o pressuposto do sujeito da ação e da autonomia como necessário à prática social e psicológica, que se preocupa com os efeitos de subjetivação, é um dos pontos nodais do campo epistêmico e ético a ser enfrentado pelos profissionais que pensam a perspectiva crítica relacionada ao subjetivo produzido no campo singular e histórico. De forma específica, a concepção de sujeito congrega os pressupostos kantianos que comportam a sobreposição entre a consciência reflexiva e a ética entendidas como atributos que possibilitam ao humano conhecer a realidade e agir sobre ela. Assim, esses pressupostos incidem na configuração de uma subjetividade sujeitada constituída na mesmidade. Eles sustentam a configuração identitária e reiteram o idêntico a si mesmo, bem como possibilitam a sobreposição dessa configuração à possibilidade de ação sobre o real.

Nessa perspectiva, nos interessa problematizar a leitura que define o homem como constituído de forma exclusiva e ideal pelo universal da consciência e da razão que deságua necessariamente no sujeito da ação e da autonomia. Ato contínuo, importa problematizar a lógica causal e linear que sustenta a ação como articulada ao agir coletivo e ético deflagrado por um conjunto composto por membros identificados a partir da mesmidade estabelecida como referência para a identidade coletiva. Assim, a história, nos trabalhos sobre as experiências do fazerse da classe trabalhadora, e a psicanálise, nas suas leituras sobre a psicologia social dos grupos, cada uma ao seu modo, configuram aportes que utilizamos para problematizar essas questôes. 


\section{CoNHECIMENTO, AÇÃO E CONSCIÊNCIA}

No cenário contemporâneo, predomina a leitura de que a unidade social mantém o potencial de emancipação, assim como a perspectiva de que as práticas locais corporificadas nos atores sociais também alimentam esse potencial. É possível ainda constatar nessas leituras que a concepção de unidade social se ancora no referencial de identidade coletiva e pressupõe a manutenção do referencial identitário. Também é importante salientar que subjacente à concepção de emancipação e autonomia há uma teoria específica sobre a organização do psiquismo que prevê a constituição do sujeito. Essa teoria adota a premissa de que a consciência recobre a subjetividade e que a razão como atributo possibilita o conhecimento sobre a realidade e o exercício da ação ética. Dessa forma, a constituição do sujeito pressupóe que o conhecimento sobre a realidade facultado pelos atributos racionais implica mudança subjetiva. Tal referencial redunda na subsequente adesão à perspectiva da emancipação calcada na teleologia de uma temporalidade histórica que se cumprirá e de um sujeito predestinado a cumprir a sua missão nessa teleologia. Não obstante, apesar de supormos a consciência como constitutiva da subjetividade, a ética como experiência a ser construída e a conquista da cidadania como alicerce para a autonomia, também acreditamos que esse pressuposto iluminista e moderno se apoia numa leitura idealizada e restrita da constituição subjetiva humana. Esse pressuposto escamoteia o trabalho dos afetos na vida psíquica ao reduzir a subjetividade à consciência, bem como pressupõe uma ordem causal sustentando a ação humana ao entender que ela seguiria uma direção ética definida a priori (Souza, 2006).

Ao longo dos denominados períodos moderno e contemporâneo da história é possível acompanhar a estreita vinculação entre a disseminação do modo de vida liberal e o modo de conhecer e de subjetivar tornado hegemônico. Sublinhamos essa questão, pois entendemos que a modernidade produz dois grandes axiomas: a representação identitária como verdade do sujeito e a ciência como verdade do saber. Por um lado, o discurso científico comporta a emergência de um sujeito que crê na possibilidade de um saber totalizante que recobre a realidade e, por outro, as identidades operam como referências para a constituição do sujeito. Esses parâmetros de verdades no plano econômico, do saber, social e subjetivo oferecem sustentação para a crescente expansão do capital e da cultura levada ao extremo nos processos de colonização e da chamada globalização (Bauman, 1999, 2001; Berman, 1986; Santos, 1988, 2004). A busca pela imposição hegemônica da assim denominada cultura ocidental é alicerçada na sua concepção como verdade e como ciência que, aparentemente, legitima a investida colonialista e intervencionista. 
Conforme apontamos no início deste artigo, a modalidade de subjetividade configurada como sujeito e hegemônica em nosso tempo presente se associa a configuraçôes históricas e sociais produzidas e sustentadas pela modernidade. Podemos entender que as redes institucional, econômica e cultural, postas a operar nesse contexto, encontram os seus esteios na organização do Estado Nação, na predominância do modo capitalista de produção, na organização do Direito centrado no contrato social e na lei universal e, por fim, mas nem por isso menos importante, na separação do público e do privado. A modernidade se constitui marcada por projetos calcados em diversas concepçôes sobre o ato de conhecer e sobre aquele que conhece. Os projetos iluminista e liberal configuram marcos na constituição do cenário moderno e, apesar da existência nesses projetos de diferentes abordagens sobre a constituição humana e sobre o conhecimento, o percurso histórico assinala que o primeiro se centra na concepção do sujeito da consciência racional e ética, obliterando o trabalho dos afetos e o limite da razão, assim como o segundo investe nas premissas da liberdade e do individual, obliterando os desígnios da igualdade e da fraternidade. Assim, apesar de leituras que apontavam tanto os limites do conhecimento impostos à consciência quanto a necessidade da crítica interna a ser por ela realizada, ganha hegemonia a concepção totalizadora e idealizada que define a consciência configurada pela razão plena capaz de controlar o real e os afetos. Em outras palavras, no percurso histórico dos últimos séculos dissemina-se e impõe-se a concepção cartesiana calcada na dissociação mente e corpo, sujeito e objeto e no controle da razão sobre os afetos. Nesse percurso a figura do sujeito sofre injunções das propostas liberais centradas nas concepçóes de indivíduo e de mercado e passa a agregar a representação identitária individualizada (Castells, 1999; Dumont, 1985; Sennett, 1988). Dessa forma, no cenário atual, a figura do sujeito compreende a subjetividade sobreposta à consciência e à razão configurada por atributos que lhe possibilitam o conhecimento pleno da realidade, da verdade e o exercício da ética a partir da ação sobre o seu entorno. Essa figura, ainda, sustenta a representação de uma unidade identitária, estabilizada no tempo e no espaço e assentada na primazia da substância e do idêntico.

As injunções entre a rede social e política e a concepção do sujeito moderno racional e ético definem a assunção à condição de cidadão centrada na participação no contrato social. O ponto de sutura entre a conquista da cidadania e os parâmetros da vida associativa é oferecido pela concepção de sujeito. Em outras palavras, a conquista da cidadania possibilitaria às pessoas ocupar um lugar objetivo e subjetivo que modificaria a sua percepção sobre o real, o outro e sobre elas mesmas, da mesma forma que permitiria o exercício da ação sobre o real a partir de uma orientação ética 
específica. Assim, no plano ideal, o sujeito ético e epistêmico apresenta essa condição a priori que, no entanto, necessita ser desenvolvida através do trabalho da escolarização, da construção da autonomia, da conquista da cidadania, para possibilitar o exercício da ação ética. Destarte, na situação em que a sua ação fosse obliterada, a justificativa seria encontrada no fato de a realidade a ser conhecida se lhe apresentar de forma transfigurada ou no fato de o aparelho conhecedor não operar corretamente. Em outras palavras, na leitura clássica, quando o sujeito não exerce a ação ou quando esta não segue os caminhos éticos esperados, entende-se que a consciência se encontra capturada pelas malhas do pensamento enredado por um fenômeno que não corresponde ao objeto que o produz. Não obstante, ao analisar essa leitura, podemos perceber que ela preserva a potência totalizadora da consciência, pois não considera os seus limites cognitivos e éticos (Derrida, 1994, 1997; Rouanet, 1985). Face a essa leitura há que no mínimo se acompanhar o percurso histórico centrado nos ideais das revoluções burguesas que sedimentaram, organizaram e possibilitaram a disseminação desses ideais. É forçoso rememorar que a Revolução Francesa de 1789 produziu o Terror e a violência como correlatos às demandas pela cidadania e pelos ideais de igualdade e de fraternidade. Nesse aspecto, é necessário recordar tanto as contribuições à ordem política e social conquistadas pelas revoluções burguesas quanto a violência praticada em nome da instauração dessa ordem. A construção da memória tornada hegemônica ao longo dos anos oblitera o período do Terror e, ato contínuo, também escamoteia o movimento histórico que produz a predominância da lógica formal e da relação causal às expensas da desqualificação de outras modalidades lógicas.

Este ponto é importante, pois diversas áreas do conhecimento centradas na perspectiva crítica alicerçada no reconhecimento do outro articulam teorias e práticas direcionadas à mudança do status quo (aqui entendido como a atual ordem social predominante pautada nos princípios do individualismo e do capitalismo). É possível observar nessas áreas do conhecimento a predominância da associação entre a ação sobre o real e a concepção da identidade coletiva. Essa associação acontece em decorrência da doutrina marxista clássica que adota uma teoria sobre o poder consoante à teoria sobre o sujeito e sobre o real. Assim, o poder estaria centrado no Estado; o sujeito da ação seria o sujeito da consciência, racional e autônomo. Nessa leitura, se prioriza o sujeito universal e a ação política se concentra na necessidade de se assenhorear do Estado. A priori, essa ação é atribuída ao coletivo configurado como uma classe social que, ao menos em tese, seria o portador de uma "missão histórica".

A leitura marxista critica as concepções que privatizam e individualizam o subjetivo e concebe o sujeito como histórico ao salientar a inserção humana no 
plano filogenético e ontogenético e o processo histórico que modula a constituição subjetiva e objetiva. Ainda, essa leitura entende a ação sobre a realidade empreendida pelo sujeito histórico a partir do amálgama dos interesses comuns, partilhados por aqueles que ocupam o mesmo lugar social entendido como a mesma posição no modo de produção. Essa leitura explicita o pressuposto de que a condição ocupada na cadeia produtiva possibilita o estabelecimento de interesses comuns por aqueles que compartilham essa condição. Em paralelo, possibilita usufruir de representaçôes similares sobre o mundo e empreender ações conjuntas, à medida que uma identidade coletiva define os contornos de um conjunto que os sustenta como sujeito histórico. Dessa forma, entendemos que a condição de uma mesmidade subjaz à identidade de um coletivo denominado classe social, bem como ancora a sua capacidade de agir e de modificar a realidade, não obstante a concepção de sujeito histórico possibilitar a crítica à perspectiva moderna de consciência autorreflexiva e individualizada.

Conforme sabemos, diversos autores, a partir de diferentes matrizes teóricas, questionam, desde uma postura crítica e transformadora, a concepção de subjetividade, de realidade e de poder que se assentam nessa leitura clássica (Castoriadis, 1987; Thompson 1987, 1991; Zizek, 1992, 2001). Primeiro, sublinha-se ao longo das últimas décadas a ação de movimentos sociais extremamente dinâmicos a questionarem as bases e os valores presentes na sociedade liberal capitalista. Ao mesmo tempo, esses movimentos desafiam as interpretações de uma vulgata do marxismo obliterada pelo economicismo, mecanicismo e autoritarismo, que reduz as concepções sobre o sujeito histórico e sobre classe social a leituras idealizadas, definidas a priori e desconectadas da realidade social e das experiências dos homens e mulheres reais. Segundo, acreditamos que, no mundo contemporâneo, uma das perguntas a serem feitas incide sobre as transformaçōes do mundo do trabalho, sobre as relações entre capital e trabalho e sobre os trabalhadores nesse contexto. Assim, desconsiderar as alterações sociais, econômicas e políticas ocorridas nas últimas décadas; continuar a situar o denominado desenvolvimento das forças produtivas como único eixo analítico; priorizar a classe proletária como agente a priori da mudança social pode revelar o não compromisso com a própria leitura social e histórica.

A título de exemplo, um autor como Thompson $(1987,1991)$, com reconhecida tradição marxista heterodoxa, ao estudar o processo de formação da classe operária inglesa, reconhece a importância da experiência singular vivenciada por homens e mulheres na sua percepção como membros de uma classe social. Trabalhar as análises thompsonianas sobre a singularidade da experiência pode ser de inestimável valia para o estudo da temática em lide. 
Nos estudos relacionados à formação da classe operária inglesa, desenvolvidos por Thompson $(1987,1991)$, experiência é fator fulcral na percepção de classe e no processo de sua constituição. Ainda, para o autor, foi a experiência histórica de lutas e resistências aos avanços do capitalismo e aos efeitos perversos desse processo nas condiçôes reais da vida dos pobres que possibilitou às plebes uma percepção de identidade de classe. Dessa forma, ele trabalha com o conceito de identidade, contudo não adota uma perspectiva mecânica e não a entende como concebida de forma apriorística. Para o autor, a ação coletiva se constituiu na base da transformação social, entretanto o sujeito não se dilui nem desaparece nessa unidade coletiva. Ele sublinha as experiências compartilhadas pelas plebes inglesas como basilares à emergência de um coletivo com percepções e aspirações comuns. Em síntese, para o autor, a consciência de classe se formaria na percepção de identidades e levaria à emergência de antagonismos entre os interesses das plebes e os projetos burgueses de sociedade, que lhes retiravam os meios de sobrevivência. Entretanto, Thompson ressalta que essas classes ainda não estariam integralmente constituídas. Assim, teríamos a emergência de lutas de classes sem que elas estivessem plenamente formadas e essas tensōes seriam fundamentais à emergência da consciência de classe, que por sua vez levaria à formação da própria classe. Para compreender esse processo, Thompson efetua de forma sistemática um movimento de expansão/contração por meio do qual atribui voz ao sujeito singular, resgatando-o do anonimato que lhe suprime os sentidos da experiência singular. Ao fazê-lo, atribui sentidos à sua ação e aponta para a importância dessa singularidade no processo de formação da identidade de classe (Munhoz, 1997).

Em decorrência, a experiência empreendida pelos sujeitos é fundamental à constituição de um novo coletivo, ao mesmo tempo que a experiência coletiva transforma a maneira de se perceber dos sujeitos que compõem esse coletivo em processo de formação. Mais do que isso, essa percepção somente se pode realizar na relação estabelecida com outra classe, também em processo de formação. Assim, classe social e consciência de classe somente podem ser pensadas como um fenômeno histórico e jamais como uma categoria abstrata, uma estrutura dada e por vezes vista de forma estática. Essa é a grande contribuição de Thompson aos estudos da ação coletiva e das lutas de classes.

Entretanto, possivelmente por injunções da tradição que associa trabalho crítico e socialmente comprometido com a vulgata marxista, leituras que divergem da proposta de ação política como articulada ao coletivo configurado a partir de referências identitárias essencializadas são lidas como reacionárias e descomprometidas com a mudança social. Um dos pontos nodais nessa discussão é encampado por setores da psicologia ao adotarem de forma cabal 
e verdadeira o pressuposto de que o sujeito da identidade coletiva é imprescindível e inelutável ao processo de reorganização subjetiva e de atuação sobre a realidade. Em nosso tempo presente, apesar de algumas reconfigurações, esse debate se mantém de forma vigorosa. Entretanto, a queda do muro de Berlin, a desagregação do mundo soviético e a correlata demolição de projetos e certezas até então inquestionáveis dentro de determinados pressupostos teóricos constituem-se em marcos históricos nodais.

O cenário acima configurado leva-nos a considerar que, por um lado, se faz necessário problematizar os referenciais clássicos associados à atividade social e psicológica, pois eles redundam na manutenção do conceito de identidade coletiva e de causalidade formal como condição imprescindível à ação sobre a realidade. Por outro, manter o referencial da identidade coletiva e da causalidade formal é uma tradição da "esquerda" que encontra grande respaldo em leituras apoiadas na versão marxista tradicional, o que gera dificuldades ao trabalho crítico realizado por setores da psicologia, das ciências sociais, da educação, dentre outros.

Nessa perspectiva, o ponto a ser problematizado diz respeito à subjetividade sujeitada restringir-se à representação identitária, pois, mesmo pensada como um ponto coagulado, mutável e dialetizável, a representação identitária implica a adoção da metafísica da presença: o presente se coagula na presença e permanece em decorrência da substantivação da subjetividade (Derrida, 1994, 1997). Não obstante, o trabalho com o referencial crítico demanda ir muito além da subjetividade sujeitada e da identidade configurada como mesmidade e repetição.

Nesse campo, consideramos pertinente e produtivo incorporar novas concepçóes e perspectivas ao trabalho dos diferentes profissionais comprometidos com a crítica ao status quo. Nesse aspecto, o aporte freudiano se constitui em importante aliado para pensar as injunções da constituição subjetiva sob a égide do singular e do coletivo, do logos - discurso - e do pathos - afetos. O aporte ao trabalho crítico pode ser encontrado nesse referencial, pois ele não opera segundo a lógica formal clássica marcada pelos pressupostos do universal, da identidade e do terceiro excluído. $\mathrm{Na}$ perspectiva freudiana, predominam referências ao processo de constituição subjetiva alicerçadas no singular, nas identificações, na pulsão, no inconsciente que, conforme sabemos, não se encontram subsumidos à concepção lógica formal. Além disso, segundo essa teoria, a pulsão e o inconsciente produzem o descentramento do sujeito e articulam a subjetividade cindida, que se contrapõe à concepção moderna da subjetividade integrada e restrita à consciência.

Sublinha-se que o conceito de identidade, em decorrência da sua associação histórica à concepção de sujeito moderno, não encontra guarida na metapsicologia freudiana. Na mesma senda, o sujeito configurado pela subjetividade restrita à 
consciência, calcado na lógica formal e no pressuposto epistêmico do cogito cartesiano, também encontra problemas para sua adoção. Assim, quando Freud fala em identificação temos a recorrência à leitura da experiência subjetiva a partir da compreensão do eu como efeito de superfície de uma ilusão de completude, que, no entanto, sempre se articula no jogo de forças com o inconsciente e com a pulsão (Freud, ([1914] 1973, [1921] 1973, [1930] 1973). Portanto, ressalte-se que a leitura freudiana não sustenta uma teoria sobre o sujeito e não trabalha com a concepção de identidade, ao menos no sentido assumido pela filosofia moderna que subsume a subjetividade à razão, à consciência e à unidade.

O eu sexualizado freudiano, marcado por sua relação com os investimentos libidinais, não se configura, portanto, como um eu autônomo. Antes, o eu sexualizado se articula às condições culturais, históricas, pulsionais, à medida que o outro é quem introduz essas marcas. Em outras palavras, o sujeito moderno configurado como um eu soberano não se articula ao eu freudiano. Ainda, com a segunda tópica, ao introduzir a ideia da pulsão de morte, ou seja, uma pulsão sem representação, Freud abandona a perspectiva da filosofia cartesiana do sujeito (Birman, 1999).

$\mathrm{Na}$ psicanálise freudiana, a temporalidade não assume a dimensão linear, desenvolvimentista e progressiva da modernidade, já que o inconsciente apresenta uma dimensão atemporal. Ainda, faz-se necessário ressaltar que na obra freudiana, apesar de a subjetividade ser constituída pela consciência, a primeira não se encontra recoberta pela segunda, à medida que a organização psíquica se produz por injunçôes conscientes, inconscientes e se constitui como singularidade. Entretanto, também é necessário mencionar que no trabalho freudiano a pulsão se agrega às representaçôes disponíveis no cenário social e histórico. Assim, o modo de subjetivar moderno, hegemônico no mundo ocidental contemporâneo, oferece às pessoas redes simbólicas específicas e práticas sociais subsumidas à crença identitária. Essas crenças deságuam na constituição de subjetividades que se reconhecem como uma unidade totalizadora fechada sobre si mesma, ou seja, elas se reconhecem como uma identidade.

Nesse contexto, o recurso ao aporte freudiano necessita ser explicitado, pois, de forma geral, não se pode reduzir, em termos teóricos ou de inscrição psíquica, o processo de identificação presente na leitura freudiana à configuração da identidade. Da mesma forma, não se pode sobrepor a subjetividade freudiana ao sujeito da ação moderno, epistêmico e identitário. De modo específico, a contribuição desse autor se revela promissora na crítica aos limites da consciência e da razão cartesiana, à medida que o inconsciente descentra e questiona a primazia da identidade e dos pressupostos epistêmicos e ontológicos universais traçados a priori e encarnados nos grupos marcados pela unidade e pela repetição. 


\section{Algumas CONSIDERAÇÕES FINAIS}

A história da psicologia centrada na perspectiva crítica é atravessada por sua vinculação com a concepção de sujeito da ação, com o pressuposto da identidade coletiva e da causalidade formal. Não obstante esse cenário, ao longo das últimas décadas tornou-se crescente a preocupação com o imbróglio teórico assente na ideia de que a perspectiva de mudança social e da ação do sujeito sobre a realidade se vincula de forma inelutável ao coletivo delineado por referências identitárias (classe, gênero, etnia, dentre outros). Nesse campo, temos uma intrincada relação entre teoria sobre o poder, concepção de sujeito e de realidade, que atravessa essas discussões.

Autores localizados em diversos campos do conhecimento e áreas de intervenção se fundamentam em ampla escala nas concepções da história, da psicanálise, das ciências sociais, da política, dentre outras, e estão a problematizar essas questôes. De forma diversa, há autores que reconhecem a constituição subjetiva como vinculada tanto à consciência e à razão, quanto ao afeto e ao inconsciente, bem como problematizam o poder como não necessariamente centrado no Estado. No cenário contemporâneo autores como Zizek (1992, 2001), Castoriadis (1987), e Butler (1997, 2003), dentre outros, a partir de diferentes perspectivas, elaboram arcabouços teóricos que oferecem leituras para a compreensão do psiquismo e da intervenção sobre a realidade que não se reduzem à perspectiva universal da subjetividade restrita à consciência e da ação associada ao sujeito da identidade coletiva. Entretanto, o problema conceitual por eles enfrentado é delicado e complexo.

Um dos pontos centrais a ser problematizado diz respeito ao pressuposto do dispositivo grupal calcado na identidade coletiva que acompanha a maioria das teorias sociais, psicológicas e as suas estratégias de intervenção. A ideia aí presente é a de que o grupo possui as condiçôes de articular o enfrentamento face ao sistema estabelecido e, ao mesmo tempo, conseguiria romper o substrato ideológico e psíquico que sustenta a concepção de indivíduo. Dessa forma, as teorias e as práticas articuladas aos movimentos sociais centradas no pressuposto da emancipação social são transpostas para as práticas psicológicas realizadas com o objetivo de produzir efeitos de subjetivação nos participantes alterando as suas concepções sobre o mundo e sobre o outro. Nesse contexto, podemos localizar uma ampla gama de atividades realizadas por profissionais que oferecem atendimentos a setores da população marginalizados no âmbito social e que vivem experiências de sofrimento e de exclusão. Pensamos aqui, por exemplo, nas práticas psicológicas calcadas no dispositivo grupal e direcionadas ao atendimento de mulheres e crian- 
ças submetidas à violência nas suas diversas manifestações; nos atendimentos oferecidos às crianças e adolescentes sob a tutela de medidas socioeducativas; aos escolares excluídos do sistema educacional; dentre outras. As práticas com esses grupos se orientam pelo pressuposto da identidade coletiva e da lógica causal, com a subjetividade restrita à conformação identitária e à conduta ética vinculada à racionalidade. Isto implica o entendimento do efeito de subjetivação associado a mudanças nas representaçôes elaboradas pelo sujeito a partir da experiência coletiva grupal calcada em interesses comuns partilhados com o outro.

O pressuposto que sustenta esse tipo de leitura se encontra na ideia de que o vínculo que funda a sociedade se localiza no reconhecimento do outro como um idêntico e na comunhão de um objetivo comum. O outro seria reconhecido e aceito a partir da sua identidade-mesmidade e do interesse compartido. $\mathrm{O}$ dispositivo grupal é uma das referências centrais utilizadas na intervenção crítica e se sustenta no pressuposto de que a identificação coletiva possibilita a criação de vínculos entre as pessoas. Ainda, outra referência nodal que sustenta esse pressuposto diz respeito à lógica formal que pressupõe a relação linear entre ativo e passivo e entre sujeito e objeto na trajetória traçada pela ação do sujeito sobre a realidade. Não menos importante é o pressuposto nessa configuração do dispositivo grupal acerca da necessidade hegemônica nesses grupos, ou seja, se organizam coletivos marcados por uma égide identitária como grupos étnicos, grupos de mulheres, de negros, de dependentes químicos, de "panicados", dentre outros. Nesses contextos, concomitante à discrepância de referenciais teóricos adotados, opera a concepção de sobreposição entre a constituição subjetiva configurada como identidade e a configuração do sintomático. Assim, a chave para o trabalho psicológico recai tanto na concepção da hermenêutica como interpretação de um sentido inerente ao sujeito, quanto na suposta comunhão de identidades entre os sintomas e a configuração psíquica. Temos aqui a sobreposição entre uma teoria do conhecimento e uma teoria acerca da constituição subjetiva que reitera a metafísica da presença, pois concebe que os sentidos associados ao sofrimento por cada um que o vivencia seriam idênticos, bem como entende que esses sentidos se encontram estabilizados e incrustados no psiquismo à espera de serem desvelados.

Desse ponto de vista, problematizar o vínculo e as relações como o cimento que modula a rede social demanda não conceituar a constituição subjetiva como subsumida aos pressupostos identitários relacionados à subjetividade, que se reconhece na repetição e reconhece o outro a partir da sua própria representação identitária. Esse trabalho crítico se justifica, pois o modo de subjetivar calcado nos pressupostos do sujeito da consciência racional, da identidade individualiza- 
da e da ordem liberal modela o fenômeno da constituição psíquica, porém não cauciona a sua constituição a esses pressupostos. Ou seja, a subjetividade sujeitada e individualizada é construída pela ordem capitalista liberal, porém essa construção se refere a um processo relacional no qual a ação no seu movimento entrelaça as instâncias envolvidas e os lugares de ativo e de passivo se entrecruzam. Dessa forma, o modo de subjetivar produtor da subjetividade sujeitada e individualizada, apesar de hegemônico, não subsume de forma plena a configuração subjetiva. Ainda, esse trabalho crítico também demanda pensar a produção de um dispositivo que possa sustentar o coletivo não mais ou não apenas como subsumido ao dispositivo calcado na identidade coletiva e no sujeito epistêmico. Essa possibilidade teórica e de intervenção abriria caminho ao singular e à sua manifestação no entrelace com o coletivo. Afinal, uma das críticas direcionadas à proposta de emancipação calcada na tradição moderna e iluminista é justamente o elogio ao universal subjacente ao sujeito epistêmico e ético.

Consideramos que o trabalho epistemológico revela o seu cunho crítico quando oferece referências e linguagem calcadas em outras concepçôes sobre o subjetivo e sobre o real que possam instrumentalizar as pessoas para a ação. Nesse aspecto, o trabalho para o qual buscamos empreender alguns aportes neste artigo se relaciona com o campo epistêmico, no sentido de produzir conhecimento que ofereça linguagem e conceitos capazes de sustentar a prática crítica a partir de parâmetros articulados às demandas do nosso tempo presente. Em outras palavras, o trabalho no campo das denominadas ciências humanas, e de forma específica na psicologia, demanda a crítica à metafísica e a produção de dispositivos para a intervenção grupal. Espera-se que esses dispositivos problematizem tanto a perspectiva ontológica que concebe o psiquismo estabilizado em um continuum espaço tempo denominado identidade quanto a concepção epistêmica calcada na hermenêutica interpretativa que pressupóe o acesso à realidade a partir do desvelar de sentidos estabelecidos a priori.

Assim, é necessário questionar até onde é possível sustentar a identidade como referencial crítico, ou seja, como forma de constituição subjetiva e de atuação sobre a realidade. Em decorrência, a irrupção do discurso do excluído tanto do universal quanto da identidade afirma novas modalidades de subjetividade e de intervenção aptas a questionar os axiomas de verdade e de unidade. Elaborar e construir referenciais teóricos críticos, assim como sustentar práticas de intervenção que possam produzir efeitos de subjetivação, parece uma tarefa desafiadora e, quem sabe, impossível. Porém o impossível é histórico; logo, o que é impossível hoje pode não o ser amanhã. 


\section{REFERÊNCIAS BIBLIOGRÁFICAS}

Bachelard, G. (1996). A formação do espirito científico. Rio de Janeiro: Contraponto.

Bauman, Z. (1999). Globalização: as consequências humanas. Rio de Janeiro: Zahar.

. (2001). Modernidade líquida. Rio de Janeiro: Jorge Zahar.

Blanche, R. (1983). A ciência atual e o racionalismo. Lisboa: Res.

Berman, M. (1986). Tudo que é sólido desmancha no ar - a aventura da modernidade. São

Paulo: Companhia das Letras.

Birman, J. (1999). Mal-estar na atualidade: a psicanálise e as novas formas de subjetivação.

Rio de Janeiro: Civilização Brasileira.

Butler, J. (1997). The psychic life of power. California: Stanford University Press.

. (2003). Problemas de gênero - feminismo e subversão da identidade. Rio de Janeiro: Civilização Brasileira.

Canguilhem, G. (1977). Ideologia e racionalidade nas ciências da vida. Portugal: Edições 70.

Castells, M. (1999). O poder da identidade. Rio de Janeiro: Paz e Terra.

Castoriadis, C. (1987). As encruzilhadas do labirinto - os domínios do homem. Rio de Janeiro: Paz e Terra.

Chauí, M. (1994). Introdução à história da filosofia. São Paulo: Brasiliense.

. (1995). Convite à filosofia. São Paulo: Ática.

Derrida, J. (1994). Espectros de Marx. O Estado da divida, o trabalho do luto e a nova Internacional. Rio de Janeiro: Relume-Dumará.

- (1997). A escritura e a diferença. São Paulo: Perspectiva.

Dumont, L. (1985). O individualismo: uma perspectiva antropológica da ideologia moderna. Rio de Janeiro: Rocco.

Freud, S. (1914). Introducción al narcisismo. Madrid: Biblioteca Nueva, 1973.

- (1921). Psicología de las masas y análisis del yo. Madrid: Biblioteca Nueva, 1973. - (1930). El malestar en la cultura. Madrid: Biblioteca Nueva, 1973.

Morin, E. (2005a). O método III: o conhecimento do conhecimento. Porto Alegre: Sulina. . (2005b). O método IV: as ideias. Porto Alegre: Sulina.

Munhoz, S. (1997). Fragmentos de um possível diálogo com Edward Palmer Thompson e com alguns dos seus críticos. Revista de História Regional, 2 (2), 153-185.

Prigogine, I. (1996). O fim das certezas: tempo, caos e as leis da natureza. São Paulo: Editora da Universidade Estadual Paulista.

Rouanet, P. S. (1985). A razão cativa - as ilusões da consciência de Platão a Freud. São Paulo: Brasiliense.

Santos, B. S. (1988). Um discurso sobre as ciências. Porto: Ediçōes Afrontamento.

Psic. Clin., Rio de Janeiro, vol.21, N.2, P.285 - 299, 2009 
. (org.) (2004). Conhecimento prudente para uma vida decente: um discurso sobre as ciências revisitado. São Paulo: Cortez.

Souza, M. (2006). Efeitos de subjetivação, práticas sociais e emancipação social: reflexões a partir de práticas psicológicas em contextos escolarizados. Coleção Oficinas do CES Centro de Estudos Sociais, 245. Coimbra: Editora da Universidade de Coimbra.

Sennett, R. (1988). O declínio do homem público: as tiranias da identidade. São Paulo: Companhia das Letras.

Thompson, E. P. (1987). A formação da classe operária inglesa. Rio de Janeiro: Paz e Terra. . (1991). Customs in Common - Studies in traditional popular culture. New York: New York Press.

Zizek, S. (1992). Eles não sabem o que fazem. Rio de Janeiro: Jorge Zahar. . (2001). El espinoso sujeto. Buenos Aires: Paidós.

Recebido em 07 de outubro de 2008 Aceito para publicação em 23 de junho de 2009 